\title{
A DEFINITION OF FORM
}

\author{
HAROLD C. BINGHAM \\ Ellsworth College
}

Regarding separate studies in form perception by Lashley and myself," the following criticism has been urged:" "Both series of experiments referred" to above are concerned with patterns, not forms." "In problem boxes such as those described by Lashley and Bingham . . . the animal tested is confronted not by two "forms" corresponding to the configurations of the opal glass, but by such designs as are suggested in figure 1 .

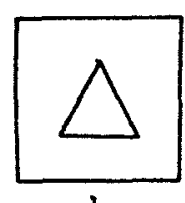

7

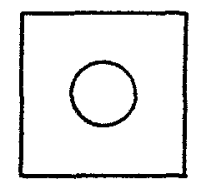

2

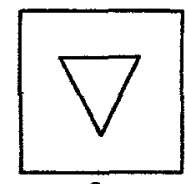

3
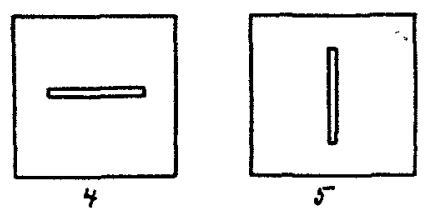

FIGURE 1. Reprinted from Jour. Animal Behavior, vol. 3, no. 5, p. 331.

The squares drawn in the figure represent the rectangular tunnels down which the animal goes in making his responses. What the animal sees is a triangle or a circle each in more or less of a square setting." In substance, the form is not without a perceptible environment and, therefore, is strictly a pattern.

Accepting the definition of pattern and conceding for the moment the definition of form urged by Hunter, I maintain that,

1 Lashley, K. S. Visual Discrimination of Size and Form in the Albino Rat. Jour. Animal Behavior, 1912, vol. 2, No. 5 .

Bingham, H. C. Size and Form Perception in Gallus Domesticus. Jour. Animal Behavior, 1913, vol. 3, No. 2.

Hunter, W. S. The Question of Form Perception. Jour. Animal Behavior, 1913 , vol. 3, No. 5, pp. 330-1. 
under the conditions as described in my paper, ${ }^{3}$ the visible stimuli presented to the animals for discrimination were forms not patterns. On page $66 \mathrm{I}$ state that the whole apparatus was set up in a dark-room. I follow this with an explanation of the only sources of illumination. On page 98 appears the plan of controlling all light factors. Now, in these conditions of control, there is to be found a refutation of the point which Hunter seeks to establish. The rectangular tunnel, to be sure, remains, but the perceptibility of the environment is wholly changed, if not destroyed. That the animals could not see the environment is attested by the fact that they were frequently observed to walk blindly into the confining walls. Not all of the time was the environment "darkened," but the control tests were always

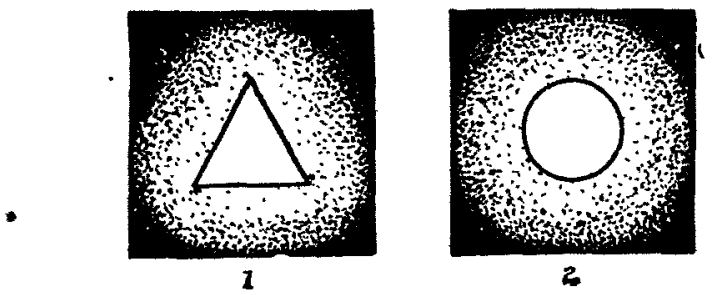

Figure 2

made to determine whether or not, among other factors, setting was a factor in discrimination.

Figure 1 does not accurately illustrate the condition of the stimulus areas. With the introduction of a screen between the general illumination and the electric boxes and with the reduction of the intensity of the source lights, a condition similar to that illustrated in figure 2 appears. In the compartment where the triangle appears, the source light fails to illuminate the corners of the tunnel, and so the perceptible portion of the setting changes to a sort of circular form as in diagram 1. About the circular stimulus the visible setting is more nearly a perfect circle as is shown in diagram 2. Even if my apparatus offered a possibility of pattern discrimination, my plan of control would have made so variable the patterns confronting the animal that they never could have served as a basis of discrimination.

Hunter has apparently missed one of the essential features of the apparatus which was used in my study. The dark-room

op. Cil. 
apparatus allows the experimenter to control the conditions of setting by means of artificial illumination. His criticism would be valid for similar experiments conducted in natural and uncontrolled light. With the visual discrimination uninfluenced by setting, the perception could not have been of patterns.

Another feature which Hunter has overlooked is one of method. Referring to figure 1, he asks:" "If an animal is trained on diagrams 1 and 2, is it any wonder that he breaks down when confronted by diagrams 2 and 3 ?" Assuming now that the animal actually sees " a triangle or a circle each in more or less of a square setting," no explanation is offered for the breaking down of the discrimination when merely the size of the form was changed, i.e., when the triangle of 1 was a circumscription or an inscription of the circle of 2. (Witness table 8, series 12, 13 and 14, March 21-22, and series 10, March 28; also table 9, series 5, Apri1 21). ${ }^{5}$

Now in these tests the patterns remained the same except in size, but the reactions changed from a high percentage of correctness to a relatively low percentage.

Besides this mis-statement of conditions there is an obvious lack of agreement in the matter of defining "form." The socalled " abstract sense " in which I have used the term has called forth objections.

In my study of form perception I was not concerned with genetic phases of the problem. My task demanded an answer to the question: Does the chick perceive forms ? ${ }^{\circ}$ Conseguently, it makes no difference whether or not the conception of form, to which I have given expression, is the result of development. One might consider that phase of the subject, but in my problem I was justified in determining whether or not the chick perceives form in this " abstract sense."

Now if our animals fail to perceive circularity and triangularity as such, there are several principles that we should not lose sight of. In the first place, we should not try to excuse our animals nor become over-dogmatic in theorizing about extraneous, or even allied problems. We should accept as a fact the conclusion to which the evidence points.

Moreover, we should seek to determine and define just what . Op. Cit., p. 331.

- Jour. Animal Behavior, 1913, vol. 3, No. 2, pp. 106 and 109.

- The task would have taken on other complexities had positive results been secured in the initial problem. 
elements our animals do perceive. In this task we need not speculate on the question whether such elements are logical or genetic precedents of form perception.

To avoid confusion, we should aroid the application of a multiple meaning to the same terminology. We should not attempt to simplify our definition of form so that this factor may be included in the animal's stock of perceptual experiences.

Finally, if we find that our animals have a power of discrimination which approaches form perception, but which is not form perception in the strict sense of the term, we should adopt a terminology to fit the special case; we should not enlarge the conception of the term "form" to cover the special case.

Perhaps "a more or less crude pattern vision" is the nearest approach to form perception that animals possess. At any rate, Hunter has done well in calling attention to the distinction between patterns and forms. However, our definition must not stop here. Two forms may be identical, but different in " shape." This would be the condition in Lashley's study. He used two identical forms in that both were rectangles $2 \mathrm{~mm}$. by $60 \mathrm{~mm}$. They differ in this respect: one is extended laterally thirty times as far as its vertical extension, while the other is extended vertically thirty times longer than laterally. Now this is a difference in "shape" of two identical forms.

Miss Washburn, in reviewing my study, ${ }^{7}$ has failed to make this distinction between form and shape. She says: "Bingham's chicks discriminated between a circle and a triangle when the apex of the triangle was on top, but since this discrimination broke down when the circle was presented with a triangle whose base was uppermost, the chick failing to choose the triangle, Bingham concludes that the chick was not reacting to form difference, but to 'the unequal stimulation of different parts of the retina.' The reviewer would conclude rather that the chicks were not possessed of an abstract idea of triangularity. A triangle with apex up is a different form from a triangle with apex down: the two have in common only the abstract quality of three-sidedness. The perception of form, as distinct from an abstract idea of form, is based precisely on the unequal stimulation of different parts of the retina."

\footnotetext{
'Washburn, M. F. Recent Literature on the Behavior of Vertebrates. Psychological Bulletin, 1913, vol. 10, No. 8, p. 320.
} 
It is not to be denied that a triangle with vertex up differs from a triangle with vertex down. But we can scarcely say that they are two different forms. They are both triangles; yes, more than that: they are equilateral triangles. Where they differ is not in form but in shape. When the extended base of the triangle is so placed as to stimulate the region of the retina which was formerly stimulated by the vertex of the triangle, a condition occurs similar to that pointed out regarding Lashley's "forms:" the forms remain identical, but the lines of maximum and minimum extension have interchanged. This fact led me to conclude in my paper ${ }^{8}$ that the apparent reactions to forms are the result of keen perception of size differences. I might have said they are due to perception of shape differences. The inversion of the triangle causes certain particular size changes-vertex or point interchanged with base or line-which causes a change in shape, but. no general change of size since the area remains constant. Similarly the factor of triangularity remains constant and the form is unchanged. Not "the perception of form," therefore, but the perception of shape "is based precisely on the unequal stimulation of different parts of the retina."

Our definition, then, as separate from the distinction between forms and patterns, must draw a line between forms and shapes. Referring to the retinal area stimulated, there is form which is general, e.g., triangle. But there is a particular feature about this general distribution of light-it is equilateral, or isosceles, or right angled-viz., shape. Forms are identical when their areas are equal and their general retinal distribution is similar. Shapes are identical when all extensions of the identical forms are equal and in the same relative directions. Thus, the area remaining constant, either or both form and shape may change. The form remaining constant, the shape may change. Change in form must.always cause change in shape.

Subsequent studies in this field should not fail to consider the factors of "shape" and "pattern" in their relation to form perception. Whatever system of control is adopted, such possible disturbances as these factors must be considered and, as far as possible, eliminated and isolated. Unquestionably my final test for form discrimination by shifting the position of the form was a severe one. Surely the factor of shape was a disturbing in-

op. Cit., p. 110. 
fluence. If, with all possible disturbing factors properly controlled, this test of shifting fail, form perception in the strict sense of that term can scarcely be said to prevail.

I have shown that the discrimination of patterns was impossible in my study. There was a possibility of discrimination on the basis of two other factors. One of the remaining factors was form: the other has been arbitrarily termed shape. The inverted triangle possessed a different shape but an identical form as compared with the upright triangle. The high percentage of correctness in reactions changed to a relatively low percentage with the inversion of the triangle. Obviously, then, form was not the basis of choice. 